\title{
A Pharmacological Examination of the Cardiovascular Effects of Malayan Krait (Bungarus candidus) Venoms
}

\author{
Janeyuth Chaisakul 1,*, Muhamad Rusdi Ahmad Rusmili ${ }^{2}$, Wayne C. Hodgson ${ }^{3, *}$, \\ Panadda Hatthachote ${ }^{4}$, Kijja Suwan ${ }^{4}$, Anjaree Inchan ${ }^{5}$, Lawan Chanhome ${ }^{6}$, \\ Iekhsan Othman ${ }^{7}$ and Krongkarn Chootip ${ }^{5}$ \\ 1 Department of Pharmacology, Phramongkutklao College of Medicine, Bangkok 10400, Thailand \\ 2 Kulliyyah of Pharmacy, International Islamic University Malaysia, Bandar Indera Mahkota, \\ Kuantan 25200, Malaysia; rusdirusmili@iium.edu.my \\ 3 Monash Venom Group, Department of Pharmacology, Biomedical Discovery Institute, Monash University, \\ Clayton, VIC 3800, Australia \\ 4 Department of Physiology, Phramongkutklao College of Medicine, Bangkok 10400, Thailand; \\ hatthachoteting@gmail.com (P.H.); kijja_suwan@yahoo.com (K.S.) \\ 5 Department of Physiology, Faculty of Medical Science, Naresuan University, Phitsanulok 65000, Thailand; \\ anjaree.in@gmail.com (A.I.); krongkarnc@gmail.com (K.C.) \\ 6 Queen Saovabha Memorial Institute, The Thai Red Cross Society, Bangkok 10330, Thailand; \\ lchanhome@yahoo.com \\ 7 Jeffrey Cheah School of Medicine and Health Sciences, Monash University Sunway Campus, \\ Bandar Sunway 46150, Malaysia; iekhsan.othman@monash.edu \\ * Correspondence: janchai1@pmk.ac.th (J.C.); wayne.hodgson@monash.edu (W.C.H.); \\ Tel./Fax: +66-2354-7752 (J.C.); +61-3-9905-4861
}

Academic Editor: Andreimar M. Soares

Received: 13 March 2017; Accepted: 24 March 2017; Published: 29 March 2017

\begin{abstract}
Cardiovascular effects (e.g., tachycardia, hypo- and/or hypertension) are often clinical outcomes of snake envenoming. Malayan krait (Bungarus candidus) envenoming has been reported to cause cardiovascular effects that may be related to abnormalities in parasympathetic activity. However, the exact mechanism for this effect has yet to be determined. In the present study, we investigated the in vivo and in vitro cardiovascular effects of B. candidus venoms from Southern (BC-S) and Northeastern (BC-NE) Thailand. SDS-PAGE analysis of venoms showed some differences in the protein profile of the venoms. B. candidus venoms $(50 \mu \mathrm{g} / \mathrm{kg}-100 \mu \mathrm{g} / \mathrm{kg}$, i.v.) caused dose-dependent hypotension in anaesthetised rats. The highest dose caused sudden hypotension (phase I) followed by a return of mean arterial pressure to baseline levels and a decrease in heart rate with transient hypertension (phase II) prior to a small decrease in blood pressure (phase III). Prior administration of monovalent antivenom significantly attenuated the hypotension induced by venoms $(100 \mu \mathrm{g} / \mathrm{kg}$, i.v.). The sudden hypotensive effect of BC-NE venom was abolished by prior administration of hexamethonium $(10 \mathrm{mg} / \mathrm{kg}$, i.v. $)$ or atropine $(5 \mathrm{mg} / \mathrm{kg}$, i.v. $)$. BC-S and BC-NE venoms $(0.1 \mu \mathrm{g} / \mathrm{kg}-100 \mu \mathrm{g} / \mathrm{mL})$ induced concentration-dependent relaxation $\left(\mathrm{EC}_{50}=8 \pm 1\right.$ and $13 \pm 3 \mu \mathrm{g} / \mathrm{mL}$, respectively) in endothelium-intact aorta. The concentration-response curves were markedly shifted to the right by pre-incubation with L-NAME $(0.2 \mathrm{mM})$, or removal of the endothelium, suggesting that endothelium-derived nitric oxide (NO) is likely to be responsible for venom-induced aortic relaxation. Our data indicate that the cardiovascular effects caused by B. candidus venoms may be due to a combination of vascular mediators (i.e., NO) and autonomic adaptation via nicotinic and muscarinic acetylcholine receptors.
\end{abstract}

Keywords: venom; Malayan krait; cardiovascular; rat; hypotension 


\section{Introduction}

Envenoming by kraits (Genus Bungarus) is common in South Asia and some regions of Southeast Asia [1-3]. There are three species of krait found in Thailand, Indonesia and Malaysia, namely, Bungarus candidus (Malayan krait), Bungarus fasciatus (banded krait) and Bungarus flaviceps (red-headed krait) [4]. In Thailand, the Malayan krait is a category 1 medically important venomous snake, a category for species causing high levels of mobility and mortality [5]. The Malayan krait is characterized by a cylindrical body with 25-36 black cross-bands separated by white interspaces [4].

Clinically, neurotoxicity is the most significant manifestation following Malayan krait envenoming, which has been attributed to the presence of pre- and post-synaptic neurotoxins in the venom [6,7]. Interestingly, symptoms which are not related to neuromuscular blockade such as hyponatremia, rhabdomyolysis, and cardiovascular disturbances including hypertension and shock have been reported in envenomed patients in Vietnam [2].

Cardiovascular disturbances following snake bite are a life-threatening phenomenon leading to morbidity and mortality in victims bitten by vipers [8] and elapids [9]. Venom-induced cardiac arrest was reported to be caused by the venom prothrombin activator, causing intravenous coagulation [10]. However, our previous studies have shown that elapid phospholipase $\mathrm{A}_{2}\left(\mathrm{PLA}_{2}\right)$ may also be responsible for cardiovascular effects causing a sudden hypotensive effect via the release of dilator autacoids and direct vascular smooth muscle relaxation [11,12].

Severe hypertension was found to be a significant outcome following Vietnamese B. candidus envenoming where $33.3 \%$ of envenomed patients displayed systolic blood pressure exceeding $150 \mathrm{mmHg}$ on two or more occasions [2]. This outcome was postulated to be due to elapid envenoming-induced autonomic dysfunction which could be due to neurotoxin blockade at presynaptic $\alpha_{2}$ - adrenoceptors, causing an increase in catecholamine release [13]. Autonomic dysfunction has been reported following Malayan krait envenoming in Thailand where victims displayed a decrease in parasympathetic activities as indicated by mydriasis, hypertension, constipation and tachycardia [14].

Krait venoms contain a wide range of proteins and peptides which may contribute to cardiovascular dysfunction including natriuretic peptides, snake venom metalloproteinases (SVMP) and $\mathrm{PLA}_{2} \mathrm{~S}$ [7]. In addition, components of snake venoms such as bradykinin potentiating peptides, L-type $\mathrm{Ca}^{2+}$ channel blockers and natriuretic peptides may contribute to cardiovascular dysfunction following envenoming [15].

Although cardiovascular disturbances seem to be a significant manifestation observed in Malayan krait envenomed patients, the mechanisms behind these effects have not been fully investigated. Further understanding of the pathology of krait envenoming-induced cardiovascular disturbances would have significant benefit in improving the management of severe krait envenoming (e.g., guiding early first aid or encouraging a focus on cardiovascular monitoring).

The aim of the current study was to determine the physiological changes in cardiovascular function following the administration of Malayan krait (B. candidus) venoms from two different geographical locations (i.e., Northeastern and Southern Thailand) in an anaesthetised rat model. We also studied the effect of Malayan krait venom on vascular function in isolated rat aorta preparations.

\section{Results}

\subsection{Sodium Dodecyl Sulphate-Polyacrylamide Gel Electrophoresis (SDS-PAGE)}

The venoms of $B$. candidus from Southern (BC-S) and Northeastern (BC-NE) Thailand were resolved in a gel under reducing and non-reducing conditions. SDS-PAGE analysis of venoms shows that there were differences in intensity and presence of protein bands (Figure 1). BC-NE venom possessed a greater number of protein bands compared to BC-S venom. Thick and high intensity bands clumped together were observed in the MW range below $17 \mathrm{kDa}$ in reduced and non-reduced BC-S venoms. High intensity protein bands of BC-NE venom were detected at a $M W<11 \mathrm{kDa}$, in reducing and non-reducing buffers. No protein band was observed within the range of $25 \mathrm{kDa}-35 \mathrm{kDa}$ 
in reduced and non-reduced BC-S venoms. At a MW of $25 \mathrm{kDa}$, reduced BC-NE venom showed an obvious protein band while non-reduced BC-NE venom displayed an incomplete separation of protein bands in the MW range of $17 \mathrm{kDa}-25 \mathrm{kDa}$.

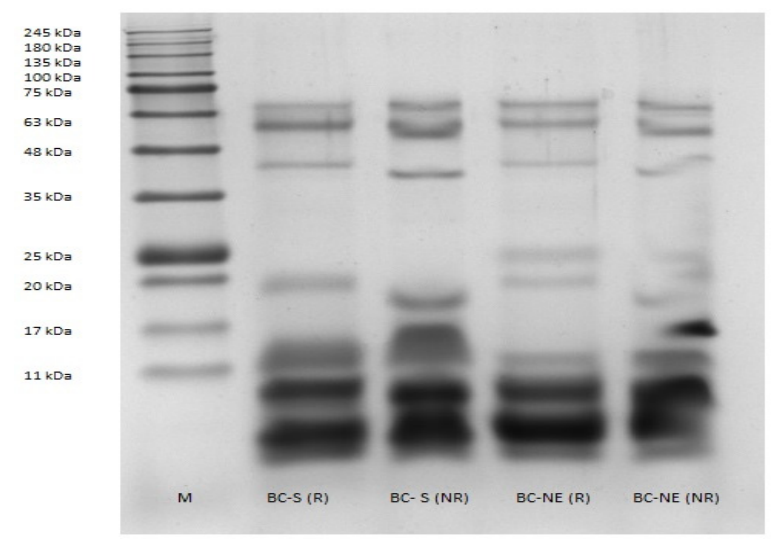

Figure 1. Sodium Dodecyl Sulphate-Polyacrylamide Gel Electrophoresis (SDS-PAGE) of venoms on a $10 \%$ separating gel with $5 \%$ stacking gel. Venoms were treated in reducing or non-reducing buffer prior to loading, electrophoresis, and stained with Coomassie Blue. M indicates the protein marker lane, BC-S indicates B. candidus venom from Southern Thailand and BC-NE indicates B. candidus venom from Northeastern Thailand. (R) indicates venom treated with reducing sample buffer and (NR) indicates venom treated with non-reducing sample buffer.

\subsection{Anaesthetised Rats}

\subsubsection{Hypotensive Effect of B. candidus Venoms}

B. candidus venoms (BC-S and BC-NE) produced a marked hypotensive effect in anaesthetised rats. BC-S and BC-NE venoms (50 $\mu \mathrm{g} / \mathrm{kg}$, i.v., Figure $2 \mathrm{a}, \mathrm{b})$ reduced mean arterial pressure (MAP) by $25 \pm 4 \%$ and $63 \pm 9 \%$, respectively $(n=4$, Figure $2 c)$ while a larger dose of BC-S and BC-NE venoms $(100 \mu \mathrm{g} / \mathrm{kg}$, i.v., $n=5-8$, Figure 2c) caused $87 \pm 5 \%$ and $94 \pm 3 \%$ reductions in MAP, respectively. Prior administration of monovalent $B$. candidus antivenom (i.e., $1 \mathrm{~mL}$ per $0.4 \mathrm{mg}$ of $B$. candidus venom) significantly attenuated the hypotensive effect of BC-S $(n=4)$ and BC-NE $(n=4)$ venoms $(100 \mu \mathrm{g} / \mathrm{kg}$, i.v., Figure $2 \mathrm{c})$.
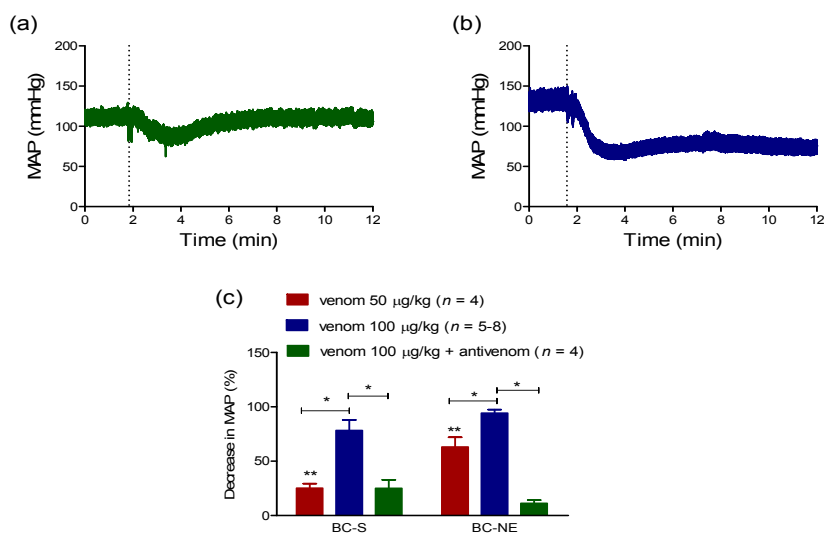

Figure 2. Traces showing the effect of (a) BC-S and (b) BC-NE venoms (50 $\mu \mathrm{g} / \mathrm{kg}$, i.v.) on MAP of anaesthetised rats. (c) Decrease in MAP following the administration of BC-S or BC-NE venom (50-100 $\mu \mathrm{g} / \mathrm{kg}$, i.v.) in the presence or absence of monovalent $B$. candidus antivenom at the recommended titer (i.e., $1 \mathrm{~mL}$ per $0.4 \mathrm{mg}$ of venom). ${ }^{*} p<0.05$, significantly different from venom $100 \mu \mathrm{g} / \mathrm{kg}$ (i.v.), Student's unpaired $t$-test. ${ }^{* *} p<0.05$, significantly different between groups, Student's unpaired $t$-test. 
2.2.2. The Recovery in MAP Following Hypotensive Effect of B. candidus Venoms

Both B. candidus venoms (BC-S and BC-NE, $100 \mu \mathrm{g} / \mathrm{kg}$, i.v.) caused marked circulatory disturbances (Figure 3a, b) as characterized by a sudden decrease in MAP, when administered to anaesthetised rats (at time point 2), followed by a slight recovery in MAP (at time point 3) with a transient hypertensive effect (at time point 4 ) being observed. Further instability of MAP was not observed for at least $20 \mathrm{~min}$ following venom administration (at time point 5). However, a recovery of cardiovascular function was not observed in $25 \%$ of animals treated (complete cardiac collapse) by BC-NE venom $(100 \mu \mathrm{g} / \mathrm{kg}$, i.v., $n=2)$.

(a)

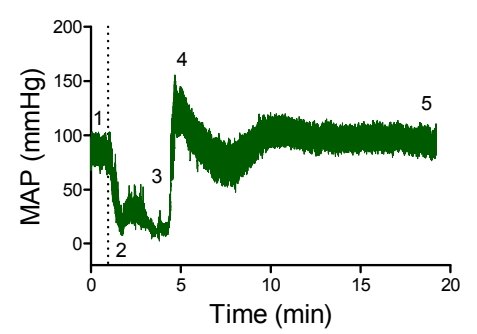

(c)

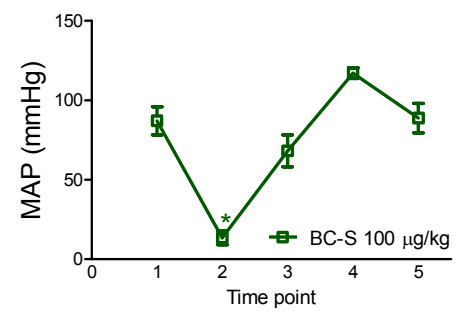

(e)

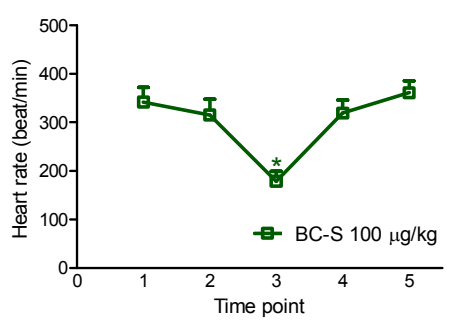

(b)

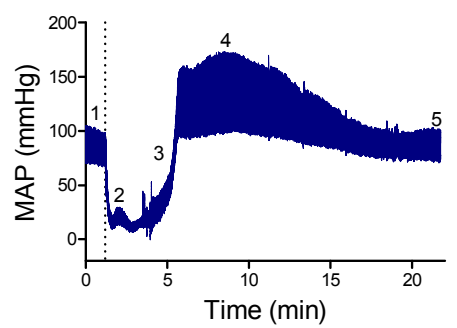

(d)

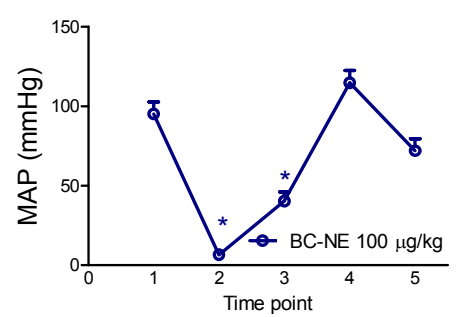

(f)

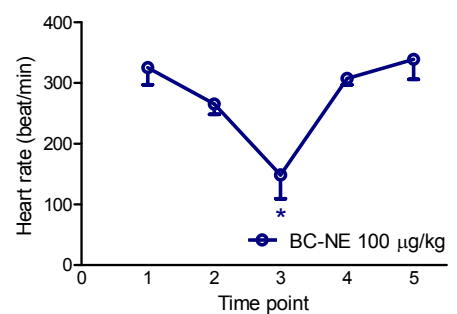

Figure 3. Traces of (a) BC-S (100 $\mu$ g/ $\mathrm{kg}$, i.v.) and (b) BC-NE venoms (100 $\mu \mathrm{g} / \mathrm{kg}$, i.v.) on MAP in an anaesthetised rat at time point 1 (before venom injection), 2 (10 s after venom injection), 3 (50\% recovery of MAP), 4 (the peak increase in MAP) and 5 (plateau in MAP, 20 min after venom injection). Effects of (c) BC-S venom $(100 \mu \mathrm{g} / \mathrm{kg}$, i.v., $n=4)$ and (d) BC-NE venom $(100 \mu \mathrm{g} / \mathrm{kg}$, i.v., $n=4)$ on MAP in different rats at time points 1, 2, 3, 4 and 5. Effects of (e) BC-S venom (100 $\mu \mathrm{g} / \mathrm{kg}, \mathrm{i} . \mathrm{v} ., n=4)$ and (f) BC-NE venom $(100 \mu \mathrm{g} / \mathrm{kg}$, i.v., $n=4)$ on heart rate in different rats at time points $1,2,3,4$ and 5 . * $p<0.05$, significantly different from time point 1 (before venom injection), Student's paired $t$-tests.

Administration of BC-S venom $(100 \mu \mathrm{g} / \mathrm{kg}$, i.v., Figure 3c) reduced MAP from $87 \pm 9 \mathrm{mmHg}$ to $13 \pm 4 \mathrm{mmHg}(n=4)$ without a significant change in heart rate at time point 2 (i.e., $342 \pm 30 \mathrm{bpm}$ to $315 \pm 32$ bpm, Figure 3e). A slight recovery in MAP was recorded 3-4 min after venom administration 
with a significant decrease in heart rate (i.e., $178 \pm 20 \mathrm{bpm}, p<0.05$, Student's paired $t$-test) at time point 3 until a hypertensive effect was observed, however this increase in MAP was not significant.

The recovery in MAP following the sudden decrease in MAP was also observed following the administration of BC-NE (100 $\mu \mathrm{g} / \mathrm{kg}$, i.v., Figure 3d) where MAP was significantly decreased from $95 \pm 7 \mathrm{mmHg}$ to $6 \pm 1 \mathrm{mmHg}(n=6, p<0.05$, Student's paired $t$-test). A recovery in cardiac function was recorded until MAP reached $114 \pm 7 \mathrm{mmHg}$, then MAP decreased to $72 \pm 7 \mathrm{mmHg}$ (Figure 3d) $20 \mathrm{~min}$ after BC-NE venom administration. A significant decrease in heart rate following the administration of BC-NE venom $(100 \mu \mathrm{g} / \mathrm{kg}$, i.v., Figure $3 \mathrm{f})$ was also recorded at time point 3 (i.e., from $325 \pm 27 \mathrm{bpm}$ at time point 1 to $148 \pm 39 \mathrm{bpm}$ at time point $3, p<0.05$, Student's paired $t$-test).

\subsubsection{Effect of BC-NE Venom on MAP in the Presence of Receptor Antagonists}

Prior administration of atropine $(5 \mathrm{mg} / \mathrm{kg}$, i.v., $n=6)$ or hexamethonium $(10 \mathrm{mg} / \mathrm{kg}$, i.v., $n=4)$, significantly attenuated the rapid hypotensive response induced by subsequent administration of BC-NE venom (100 $\mu \mathrm{g} / \mathrm{kg}$, i.v.) compared to vehicle control (saline, Figure $4 \mathrm{~b}, n=5)$. In contrast, the hypotensive effect of BC-NE $(100 \mu \mathrm{g} / \mathrm{kg}$, i.v. $)$ was not significantly attenuated by prior administration of heparin (300 units $/ \mathrm{kg}$, i.v., $n=3)(p<0.05$, one-way ANOVA, Figure $4 \mathrm{~b})$.

(a)

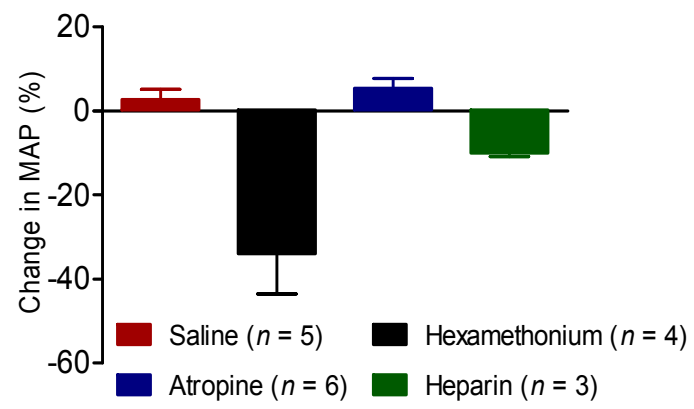

(b)

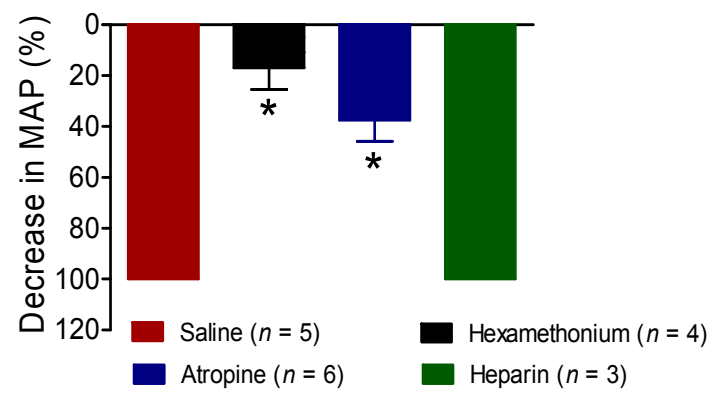

Figure 4. (a) Change in MAP of anaesthetised rats following the administration of saline $(n=5)$, hexamethonium $(10 \mathrm{mg} / \mathrm{kg}$, i.v., $n=4)$, atropine $(5 \mathrm{mg} / \mathrm{kg}$, i.v., $n=6)$ or heparin (300 units $/ \mathrm{kg}$, i.v., $n=3$ ); (b) Effect of B. candidus venom from Northeastern Thailand (BC-NE; $100 \mu \mathrm{g} / \mathrm{kg}$, i.v.) in the absence and presence of hexamethonium, atropine and heparin. ${ }^{*} p<0.05$, is significantly different from saline, one-way ANOVA.

\subsection{Effect of B. candidus Venoms on Rat Aortic Rings}

The effects of $B$. candidus venoms were determined on isolated phenylephrine pre-contracted rat aorta. BC-S and BC-NE venoms $(0.1 \mu \mathrm{g} / \mathrm{mL}-100 \mu \mathrm{g} / \mathrm{mL}, n=4)$ induced concentration-dependent relaxations in endothelium-intact aorta $\left(\mathrm{EC}_{50}=8 \pm 1\right.$ and $13 \pm 3 \mu \mathrm{g} / \mathrm{mL}$, respectively). In endothelium-denuded arteries, the concentration-relaxation curve was significantly shifted to the right in the presence of BC-S (Figure $5 \mathrm{a}, \mathrm{EC}_{50}=19 \pm 4 \mu \mathrm{g} / \mathrm{mL}, n=4$ ) or BC-NE (Figure $5 \mathrm{~b}$, $\left.\mathrm{EC}_{50}=22 \pm 3 \mu \mathrm{g} / \mathrm{mL}, n=4\right)$ venoms.

In addition, a significant rightward shift of the concentration relaxation curves in endothelium-intact aorta was observed when L-NAME $(0.2 \mathrm{mM})$ was added prior to the addition of BC-S (Figure $5 \mathrm{e}$, $\mathrm{EC}_{50}=20 \pm 10 \mu \mathrm{g} / \mathrm{mL}, n=5$ ) or BC-NE (Figure $5 \mathrm{f}, \mathrm{EC}_{50}=32 \pm 11 \mu \mathrm{g} / \mathrm{mL}, n=5$ ) venoms. However, indomethacin $(10 \mu \mathrm{M})$ did not cause a significant rightward shift of the concentration-relaxation curve to either BC-S (Figure $5 c, n=5$ ) or BC-NE (Figure $5 d, n=5$ ) venom in endothelium-intact aorta. Both venoms $(0.1 \mu \mathrm{g} / \mathrm{mL}-100 \mu \mathrm{g} / \mathrm{mL})$ failed to induce aortic contraction in endothelium-intact aorta ( $n=3$, data not shown). 
(a)

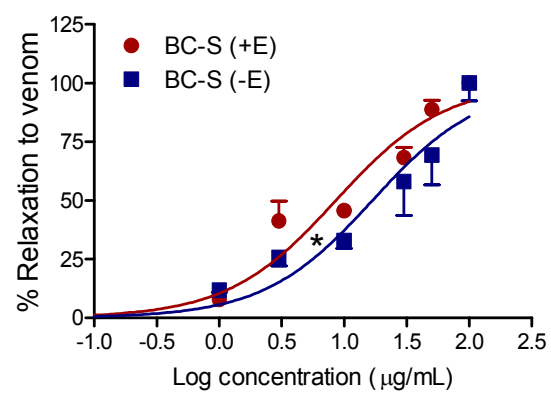

(c)

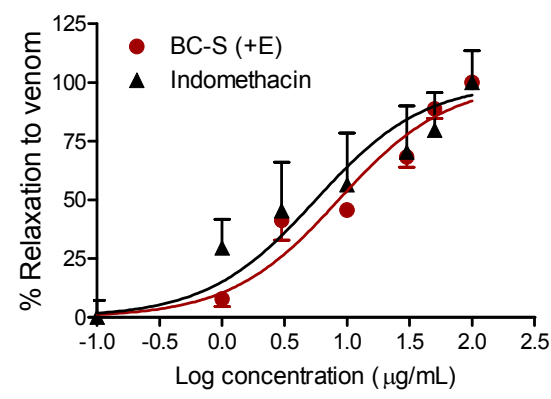

(e)

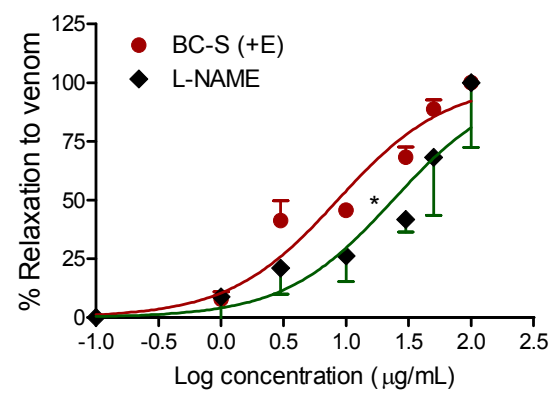

(b)

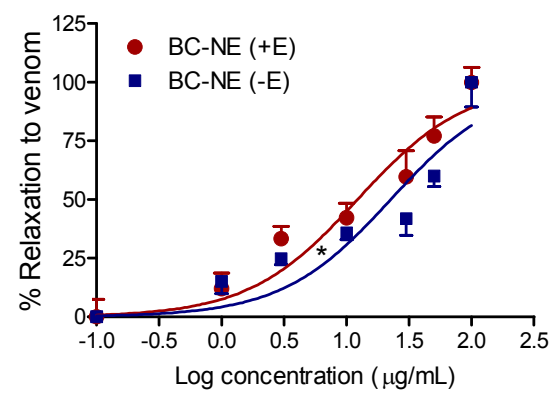

(d)

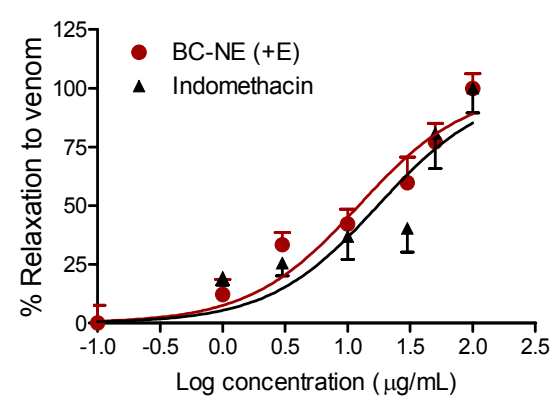

(f)

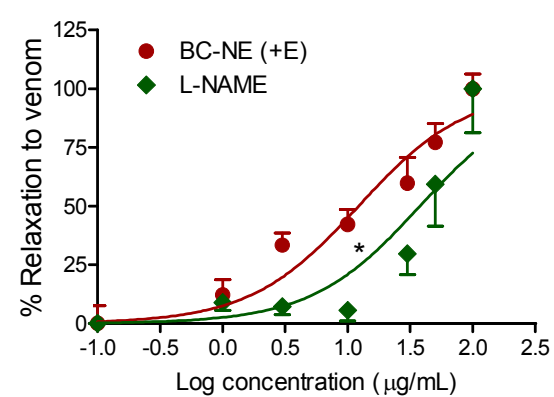

Figure 5. Concentration-response curves to (a) BC-S and (b) BC-NE venoms $(0.1 \mu \mathrm{g} / \mathrm{mL}-100 \mu \mathrm{g} / \mathrm{mL})$ in endothelium-intact and endothelium-denuded rat aortic rings $(n=4)$. Relaxation effect of $(\mathbf{c})$ BC-S and (d) BC-NE venoms on endothelium-intact rat aortic rings in the presence and absence of indomethacin $(10 \mu \mathrm{M}, n=5)$. Relaxation effect of (e) BC-S and (f) BC-NE venoms on endothelium-intact rat aortic rings in the presence and absence of L-NAME $(0.2 \mathrm{mM}, n=5) .{ }^{*} p<0.05$, is significantly different, Student's unpaired $t$-test.

\section{Discussion}

Malayan krait (Bungarus candidus) is an elapid species found in Southeast Asia. The venom contains highly potent neurotoxins that inhibit neurotransmission at the neuromuscular junction [6]. Interestingly, symptoms involving cardiovascular function such as tachycardia and blood pressure irregularities which are not related to the neuromuscular blocking activity of the venom have been reported in some victims [2]. So far, the potential mechanisms behind these cardiovascular events have yet to be identified.

Previous studies have shown that animal venom composition is associated to season, habitat, prey type, inter-and intra-species including geographical variation $[16,17]$. These variations can be clinically significant as they can produce different outcomes following envenoming e.g., differences in 
cytotoxicity and cardiovascular effects [17]. In the present study, the protein band profiles of Malayan krait venoms from Northeastern and Southern Thailand were determined using SDS-PAGE analysis. In the reducing buffer, both venoms displayed less protein bands compared to non-reduced venoms indicating the presence of high amounts of protein complexes in both venoms. There were also notable differences between the venoms in the presence and intensity of protein bands at $25 \mathrm{kDa}$, suggesting variation in venom composition that could be due to geographical differences. In reducing and non-reducing buffers, both venoms showed thick and high protein bands in the MW range below $17 \mathrm{kDa}$ which would likely be due to presynaptic $\mathrm{PLA}_{2}$ and three-finger neurotoxins [18].

In our experiments, the effect of geographical variation of Malayan krait venoms on hypotensive effect was significant, observed in animals receiving the lower $(50 \mu \mathrm{g} / \mathrm{kg}$, i.v.) but not the higher $(100 \mu \mathrm{g} / \mathrm{kg}$, i.v.) dose of venom. The mechanisms behind Malayan krait venom-induced hypotension have been postulated to include $\mathrm{Ca}^{2+}$ channel blocker activity [19] and the presence of natriuretic peptides $[7,20]$. Indeed, the proteomic profile of B. candidus venom indicated the presence of a natriuretic peptide but not $\mathrm{Ca}^{2+}$ channel blocker [7]. Moreover, autonomic dysfunction due to a blockade of adrenoceptors by elapid neurotoxins has been suggested to contribute to the hypertension observed following snake envenoming [13]. Interestingly, both episodes of hypertension or hypotension associated with shock have been observed following krait envenoming in a similar number of patients (33.3\% and $31 \%$, respectively) [2].

In the present study, BC-S and BC-NE venoms $(50 \mu \mathrm{g} / \mathrm{kg}-100 \mu \mathrm{g} / \mathrm{kg}$, i.v. $)$ produced a dose-dependent hypotensive effect. However, venoms did not significantly alter heart rate as indicated by a comparison of heart rate immediately prior to venom injection and then again at the time point where MAP had decreased by $80 \%$. Administration of venom at the higher dose (i.e., $100 \mu \mathrm{g} / \mathrm{kg}$, i.v.) caused a triphasic effect which was characterized by an immediate decrease in blood pressure (phase I), followed by a transient hypertension (phase II) and then a return to basal levels with a slight reduction in MAP (phase III). The return of MAP following envenoming is similar to the effect of snake venom $\mathrm{PLA}_{2}$ [12] and giant jellyfish Nemopilema nomurai venom [21]. Moreover, complete cardiovascular collapse was observed in some animals administered BC-NE, but not BC-S, venom (100 $\mu \mathrm{g} / \mathrm{kg}$, i.v.).

In the current study, a significant bradycardia was observed at time point 3 where MAP had recovered by approximately $50 \%$. However, we did not observe tachycardia which is different from a previous clinical report in which three victims displayed an increase in heart rate [14]. This might be due to differences in the response of different species [22] or an effect of anesthetic which can blunt reflex responses [23].

Heparin has been postulated to inhibit histamine release from canine mast cells [24]. In a previous study, prior administration of heparin protected rats from Papuan taipan (Oxyuranus scutellatus) venom-induced cardiovascular collapse, suggesting the involvement of anaphylactic mediator release [11]. In the current study, heparin did not inhibit B. candidus venom-induced hypotension, suggesting also that the release of histamine is not associated with this response. However, the effects of Malayan krait venom were markedly attenuated by pre-treatment with hexamethonium or atropine, indicating the involvement of ganglionic nicotinic and autonomic muscarinic receptors, respectively.

Antivenom is the only reliable treatment for systemically envenomed patients [25]. The Queen Saovabha Memorial Institute (Thai Red Cross Society, Bangkok, Thailand) is a manufacturer of antivenoms for medically important Southeast Asian snake species. Administration of B. candidus antivenom prevented hypotension from Malayan krait venom in anaesthetised rats. This indicates that the toxins that induce hypotension in the venoms are antigenically homologous.

In vascular experiments, the venoms caused concentration-dependent relaxation in both endothelium-intact and endothelium-denuded rat aortae. Relaxation curves were shifted to the right when the tissues were pre-incubated with the nitric oxide (NO) synthase inhibitor, L-NAME or removal of the endothelium, suggesting that the endothelium-dependent relaxant effect is mediated by NO. However, this effect requires further investigation in different vascular beds. In our previous studies in rat mesenteric artery preparations, the relaxant effect of Papuan taipan venom and its 
purified $\mathrm{PLA}_{2}$ involved a combination of the release of dilator autacoids (i.e., $\mathrm{PGI}_{2}$ ) and a direct effect on vascular smooth muscle which was attenuated by indomethacin and the protein kinase A inhibitor, Rp-8-CPT-cAMP [11,12]. This venom-induced vasodilation may assist the elapid neurotoxins to reach their targets. The transient hypertensive response observed following sudden hypotension may not be due to a direct effect of venom on the vasculature as venom-induced contraction was not observed in aortae experiments. In addition, there was no significant difference in the relaxation caused by BC-S and $\mathrm{BC}-\mathrm{NE}$ venoms, indicating that the venom components that cause relaxation are present in venom from snakes from both localities.

We have demonstrated that Thai B. candidus causes profound cardiovascular effects characterized by sudden hypotension, and activation of autonomic cardiovascular reflexes. Further purification and characterisation of the venom components responsible for the cardiovascular activities may enable the better management of Malayan krait envenoming.

\section{Conclusions}

These data indicate that the cardiovascular disturbance observed after envenoming by Malayan krait may involve autonomic reflex and vascular nitric oxide mechanisms. Early basic life support and monitoring of cardiovascular function may be required to prevent and manage the life-threatening outcomes.

\section{Materials and Methods}

\subsection{Venom Preparation and Storage}

Freeze-dried Malayan krait (B. candidus) venoms were obtained from Queen Saovabha Memorial Institute (QSMI) of the Thai Red Cross Society, Bangkok, Thailand. The venoms were milked and pooled from specimens collected in Nakhon Ratchasima, Northeastern Thailand (BC-NE) and Nakhon Si Thammarat, Southern Thailand (BC-S). The snake venoms from each region were milked by directly attaching a microhaematocrit tube on each fang. The collected venom was then transferred to a $1.5 \mathrm{~mL}$ microcentrifuge tube, frozen at $-20^{\circ} \mathrm{C}$ and freeze-dried. Freeze-dried venom samples were weighed, labeled and stored at $-20^{\circ} \mathrm{C}$ prior to use. When required, the venoms were weighed and dissolved in distilled water. Dissolved venoms were kept on ice during experiments.

\subsection{Protein Concentration Determination}

Venom protein content was determined using a BCA Protein Assay Kit (Pierce Biotechnology, Rockford, IL, USA) as per the manufacturer's instructions. Briefly, $25 \mu \mathrm{L}$ of protein was loaded onto a 96-well plate in triplicate, then $200 \mu \mathrm{L}$ reagent buffer mix was added to each well. The plate was incubated at $37^{\circ} \mathrm{C}$ for $30 \mathrm{~min}$, then read at $562 \mathrm{~nm}$ using a plate reader spectrophotometer (Enspire multimode plate reader, Waltham, MA, USA). Protein concentration was determined from the standard curve.

\subsection{Sodium Dodecyl Sulphate-Polyacrylamide Gel Electrophoresis (SDS-PAGE)}

Venoms $(12.5 \mu \mathrm{g})$ in reducing and non-reducing sample buffers were resolved and electrophoresed at $90 \mathrm{~V}$ in 10\% separating gel with 5\% stacking gel using the method previously described [26]. Protein bands were visualized by staining with Bio-Safe Coomassie G-250 solution (Bio-Rad Laboratories; Hercules, CA, USA), followed by de-staining using distilled water. BLUelf Prestained Protein Ladder (GeneDirex, Taiwan) was electrophoresed in the gel as protein molecular weight marker. The gel was scanned using the Fusion FX (Vilber Lourmat, Collegien, France).

\subsection{Anaesthetised Rat Preparation}

Male Sprague-Dawley rats weighting $280 \mathrm{~g}-330 \mathrm{~g}$ were anaesthetised with pentobarbital sodium (50 mg/kg-70 mg/kg, i.p.). Additional anaesthetic was administered throughout the experiment 
as required. A midline incision was made in the cervical region, and cannulae were inserted into the trachea, jugular vein and carotid artery, for artificial respiration (if required) and administration of drugs/venom and measurement of blood pressure, respectively. Arterial blood pressure was recorded using a Gould Statham P23 pressure transducer filled with heparinised saline $(25 \mathrm{U} / \mathrm{mL})$. Systemic blood pressure was monitored on a MacLab system (ADInstruments). At the conclusion of the experiment, the animals were killed by an overdose of pentobarbitone (i.v.). Pulse pressure was defined as the difference between systolic and diastolic blood pressures. Mean arterial pressure (MAP) was defined as diastolic blood pressure plus one-third of pulse pressure. The rats were kept under a heat lamp during the experiment.

Where indicated, hexamethonium bromide $10 \mathrm{mg} / \mathrm{kg}$ (i.v.) [27] or atropine $5 \mathrm{mg} / \mathrm{kg}$ (i.v.) [11] were administered to inhibit autonomic ganglionic and muscarinic receptors, respectively. Heparin (300 U/kg, i.v.) was administered to block the release of histamine [28]. Monovalent B. candidus antivenom (Lot No.: BC00115) at the recommended titer (i.e., $1 \mathrm{~mL}$ per $0.4 \mathrm{mg}$ of B. candidus venom) was administered via the jugular vein (i.v. bolus). Control rats were injected with the same volume of normal saline $(0.9 \%$ sodium chloride, i.v.). All drugs, saline and antivenom were given 15 min prior to venom administration.

\subsection{Isolation and Study of Rat Aortic Ring}

Male Wistar rats (200 g-250 g) were anaesthetised with sodium pentobarbital $(50 \mathrm{mg} / \mathrm{kg}-70 \mathrm{mg} / \mathrm{kg}$, i.p.), then the chest was cut open and the thoracic aorta removed and placed in ice-cold physiological saline solution (PSS) composed of (mM): $\mathrm{NaCl} 122 ; \mathrm{KCl}$ 5; (N-(2-hydroxyethyl)piperazine N'-(2-ethanesulfonic acid)) (HEPES) 10; $\mathrm{KH}_{2} \mathrm{PO}_{4} 0.5 ; \mathrm{NaH}_{2} \mathrm{PO}_{4} 0.5 ; \mathrm{MgCl}_{2} 1$; glucose 11 ; and $\mathrm{CaCl}_{2}$ 1.8, $\mathrm{pH}$ adjusted to 7.3 with $\mathrm{NaOH}$. The aorta was cleared of surrounding loose connective tissue and fat, and cut into $2 \mathrm{~mm}-5 \mathrm{~mm}$ lengths. Where indicated, the endothelium was removed by gently rubbing the intimal surface with a thin stainless steel wire. Aortic rings were mounted on a pair of intraluminal wires in tissue chambers containing PSS as described previously [29]. Pre-heated PSS ( $3 \mathrm{~mL}$ ) was added to the bath, bubbled with air and maintained at $37^{\circ} \mathrm{C}$. Tissue segments were allowed to equilibrate for $1 \mathrm{~h}$ at a resting tension of $1 \mathrm{~g}$ during which time the solution was changed every $15 \mathrm{~min}$. An intact endothelium was confirmed by a maximal relaxation to $10 \mu \mathrm{M}$ acetylcholine (ACh) in tissues precontracted with a sub-maximal concentration of phenylephrine $(1 \mu \mathrm{M})$. Arteries that produced relaxations greater than $80 \%$ were considered to have an endothelium intact. Cumulative vasorelaxation responses to venom $(0.1 \mu \mathrm{g} / \mathrm{mL}-100 \mu \mathrm{g} / \mathrm{mL})$ were performed in both endothelium-intact and endothelium-denuded aortic rings. The isometric tension was measured using a force transducer (CB Sciences Inc., Milford, CT, USA) connected to a MacLab system (ADInstruments).

Where indicated, L-NAME $(0.2 \mathrm{mM})$ and indomethacin $(10 \mu \mathrm{M})$ [30] were used to inhibit NO production and prostaglandin production, respectively.

\subsection{Chemical and Drugs}

Monovalent B. candidus antivenom (Lot No.: BC00115) was purchased from Queen Saovabha Memorial Institute (QSMI) of the Thai Red Cross Society, Bangkok, Thailand. The following drugs and solutions were purchased from Sigma Aldrich (St. Louis, MO, USA): ACh, L-NAME, indomethacin, atropine and hexamethonium bromide. Heparin was obtained from LEO Pharma (Ballerup, Denmark).

\subsection{Data Analysis and Statistics}

Statistical analysis was performed using Prism 6.0 software (GraphPad Software, La Jolla, CA, USA). Student's unpaired $t$-test performed on venom responses in the presence of venoms in different animals and tissues, and paired $t$-tests were used to compare responses before and after venom/agonist in the same animal or tissue. Multiple comparisons were made using a one-way analysis of variance (ANOVA) followed by Tukey's multiple comparison. Values of $p<0.05$ were accepted as significant. Data were expressed as mean \pm SEM. 


\subsection{Animal Ethics}

The rats were purchased from the National Laboratory Animal Centre, Mahidol University, Salaya, Nakhon Pathom, Thailand. The animals were housed with free access to food and drinking water. Approval for all experimental procedures was granted by the Subcommittee for Multidisciplinary Laboratory and Animal Usage, Phramongkutklao College of Medicine and the Animal Ethics Committee, Naresuan University (Permits for approved experiments: NU-AEE590506).

Acknowledgments: The authors wish to acknowledge the Office of Research Development, Phramongkutklao College of Medicine \& Phramongkutklao Hospital (ORD, PCM \& PMK), Bangkok, Thailand. Janeyuth Chaisakul was funded by a National Science and Technology Development Agency (NSTDA) of the Royal Thai Government Award (SCH-NR2015-382).

Author Contributions: J.C., M.R.A.R., W.C.H. and K.C. conceived and designed the experiments; J.C., M.R.A.R., A.I., P.H., K.S., I.O., L.C. and K.C. performed the experiments; J.C., M.R.A.R., A.I. and K.C. analyzed the data; J.C., M.R.A.R., W.C.H., P.H., K.S., A.I., L.C., I.O. and K.C. all contributed to the writing of the manuscript.

Conflicts of Interest: The authors declare no conflict of interest and the founding sponsors had no role in the design of the study; in the collection, analyses, or interpretation of data; in the writing of manuscript, and in the decision to publish the results.

\section{References}

1. Silva, A.; Maduwage, K.; Sedgwick, M.; Pilapitiya, S.; Weerawansa, P.; Dahanayaka, N.J.; Buckley, N.A.; Johnston, C.; Siribaddana, S.; Isbister, G.K. Neuromuscular effects of common krait (Bungarus caeruleus) envenoming in Sri Lanka. PLoS Negl. Trop. Dis. 2016. [CrossRef]

2. Trinh, K.X.; Khac, Q.L.; Trinh, L.X.; Warrell, D.A. Hyponatraemia, rhabdomyolysis, alterations in blood pressure and persistent mydriasis in patients envenomed by Malayan kraits (Bungarus candidus) in southern Vietnam. Toxicon 2010, 56, 1070-1075. [PubMed]

3. Viravan, C.; Looareesuwan, S.; Kosakarn, W.; Wuthiekanun, V.; McCarthy, C.J.; Stimson, A.F.; Bunnag, D.; Harinasuta, T.; Warrell, D.A. A national hospital-based survey of snakes responsible for bites in Thailand. Trans. R. Society. Trop. Med. Hyg. 1992, 86, 100-106. [CrossRef]

4. Chanhome, L.; Cox, M.J.; Vasaruchapong, T.; Chaiyabutr, N.; Sitprija, V. Characterization of venomous snakes of Thailand. Asian Biomed. 2011, 5, 311-328.

5. WHO. Venomous snakes of the south-east asia region, their venoms and pathophysiology of human envenoming. In Guidelines for the Management of Snake-Bites, 2nd ed.; WHO: Geneva, Switzerland, 2016; Volume 2.

6. Khow, O.; Chanhome, L.; Omori-Satoh, T.; Ogawa, Y.; Yanoshita, R.; Samejima, Y.; Kuch, U.; Mebs, D.; Sitprija, V. Isolation, toxicity and amino terminal sequences of three major neurotoxins in the venom of Malayan krait (Bungarus candidus) from Thailand. J. Biochem. 2003, 134, 799-804. [CrossRef] [PubMed]

7. Rusmili, M.R.; Yee, T.T.; Mustafa, M.R.; Hodgson, W.C.; Othman, I. Proteomic characterization and comparison of Malaysian Bungarus candidus and Bungarus fasciatus venoms. J. Proteom. 2014, 110, 129-144. [CrossRef] [PubMed]

8. Silva, A.; Pilapitiya, S.; Siribaddana, S. Acute myocardial infarction following a possible direct intravenous bite of Russell's viper (Daboia russelli). BMC Res. Notes 2012. [CrossRef] [PubMed]

9. Chaisakul, J.; Isbister, G.K.; Kuruppu, S.; Konstantakopoulos, N.; Hodgson, W.C. An examination of cardiovascular collapse induced by eastern brown snake (Pseudonaja textilis) venom. Toxicol. Lett. 2013, 221, 205-211. [CrossRef] [PubMed]

10. Tibballs, J.; Sutherland, S.K.; Rivera, R.A.; Masci, P.P. The cardiovascular and haematological effects of purified prothrombin activator from the common brown snake (Pseudonaja textilis) and their antagonism with heparin. Anaesth. Intensiv. Care 1992, 20, 28-32.

11. Chaisakul, J.; Isbister, G.K.; Konstantakopoulos, N.; Tare, M.; Parkington, H.C.; Hodgson, W.C. In vivo and in vitro cardiovascular effects of Papuan taipan (Oxyuranus scutellatus) venom: Exploring "sudden collapse". Toxicol. Lett. 2012, 213, 243-248. [PubMed]

12. Chaisakul, J.; Isbister, G.K.; Tare, M.; Parkington, H.C.; Hodgson, W.C. Hypotensive and vascular relaxant effects of phospholipase A2 toxins from Papuan taipan (Oxyuranus scutellatus) venom. Eur. J. Pharmacol. 2014, 723, 227-233. [CrossRef] [PubMed] 
13. Agarwal, R.; Aggarwal, A.N.; Gupta, D. Elapid snakebite as a cause of severe hypertension. J. Emerg. Med. 2006, 30, 319-320. [CrossRef] [PubMed]

14. Laothong, C.; Sitprija, V. Decreased parasympathetic activities in Malayan krait (Bungarus candidus) envenoming. Toxicon 2001, 39, 1353-1357. [CrossRef]

15. Joseph, R.; Pahari, S.; Hodgson, W.C.; Kini, R.M. Hypotensive agents from snake venoms. Current. Drug Targets. Cardiovasc. Haematol. Disord. 2004, 4, 437-459. [CrossRef]

16. Chippaux, J.P.; Williams, V.; White, J. Snake venom variability: Methods of study, results and interpretation. Toxicon 1991, 29, 1279-1303. [CrossRef]

17. Winter, K.L.; Isbister, G.K.; McGowan, S.; Konstantakopoulos, N.; Seymour, J.E.; Hodgson, W.C. A pharmacological and biochemical examination of the geographical variation of Chironex fleckeri venom. Toxicol. Lett. 2010, 192, 419-424. [CrossRef] [PubMed]

18. Rusmili, M.R.; Yee, T.T.; Mustafa, M.R.; Othman, I.; Hodgson, W.C. In-vitro neurotoxicity of two Malaysian krait species (Bungarus candidus and Bungarus fasciatus) venoms: Neutralization by monovalent and polyvalent antivenoms from Thailand. Toxins 2014, 6, 1036-1048. [CrossRef] [PubMed]

19. Chanhome, L.; Sitprija, V.; Chaiyabutr, N. Effect of Bungarus candidus (Malayan krait) venom on general circulation and renal hemodynamics in experimental animals. Asian Biomed. 2010, 4, 421-428.

20. Siang, A.S.; Doley, R.; Vonk, F.J.; Kini, R.M. Transcriptomic analysis of the venom gland of the red-headed krait (Bungarus flaviceps) using expressed sequence tags. BMC Mol. Biol. 2010, 11, 24.

21. Kim, E.; Lee, S.; Kim, J.S.; Yoon, W.D.; Lim, D.; Hart, A.J.; Hodgson, W.C. Cardiovascular effects of Nemopilema nomurai (scyphozoa: Rhizostomeae) jellyfish venom in rats. Toxicol. Lett. 2006, 167, $205-211$. [CrossRef] [PubMed]

22. Hart, A.J.; Isbister, G.K.; O'Donnell, P.; Williamson, N.A.; Hodgson, W.C. Species differences in the neuromuscular activity of post-synaptic neurotoxins from two Australian black snakes (Pseudechis porphyriacus and Pseudechis colletti). Toxicol. Lett. 2013, 219, 262-268. [CrossRef] [PubMed]

23. Hanamoto, H.; Niwa, H.; Sugimura, M.; Morimoto, Y. Autonomic and cardiovascular effects of pentobarbital anesthesia during trigeminal stimulation in cats. Int. J. Oral Sci. 2012, 4, 24-29. [CrossRef] [PubMed]

24. Inase, N.; Schreck, R.E.; Lazarus, S.C. Heparin inhibits histamine release from canine mast cells. Am. J. Physiol. 1993, 264, L387-L390. [PubMed]

25. Johnston, C.I.; Ryan, N.M.; O’Leary, M.A.; Brown, S.G.; Isbister, G.K. Australian taipan (Oxyuranus spp.) envenoming: Clinical effects and potential benefits of early antivenom therapy - Australian snakebite project (asp-25). Clin. Toxicol. (Phila) 2017, 55, 115-122. [CrossRef] [PubMed]

26. Laemmli, U.K. Cleavage of structural proteins during the assembly of the head of bacteriophage t4. Nature 1970, 227, 680-685. [CrossRef] [PubMed]

27. Ismail, A.; Mohamed, M.; Sulaiman, S.A.; Wan Ahmad, W.A. Autonomic nervous system mediates the hypotensive effects of aqueous and residual methanolic extracts of Syzygium polyanthum (wight) walp. Var. Polyanthum leaves in anaesthetized rats. Evidence.-Based Complement. Altern. Med.: ECAM 2013. [CrossRef] [PubMed]

28. Tibballs, J.; Sutherland, S.K. The efficacy of heparin in the treatment of common brown snake (Pseudonaja textilis) envenomation. Anaesth. Intensiv. Care 1992, 20, 33-37.

29. Kamkaew, N.; Scholfield, C.N.; Ingkaninan, K.; Maneesai, P.; Parkington, H.C.; Tare, M.; Chootip, K. Bacopa monnieri and its constituents is hypotensive in anaesthetized rats and vasodilator in various artery types. J. Ethnopharmacol. 2011, 137, 790-795. [CrossRef] [PubMed]

30. Crachi, M.T.; Hammer, L.W.; Hodgson, W.C. A pharmacological examination of venom from the Papuan taipan (Oxyuranus scutellatus canni). Toxicon 1999, 37, 1721-1734. [CrossRef]

(C) 2017 by the authors. Licensee MDPI, Basel, Switzerland. This article is an open access article distributed under the terms and conditions of the Creative Commons Attribution (CC BY) license (http:/ / creativecommons.org/licenses/by/4.0/). 